\title{
The Relationship between Retinopathy Based on Direct Ophthalmoscope Examination with Cognitive Impairment in Hypertensive Patients
}

\author{
Yetty Ramli ${ }^{1}$, Eva Dewati ${ }^{2}$, Mellia Ambarningrum ${ }^{3 *}$, Elvioza $^{4}$ \\ 1,2,3 Departement of Neurology, Faculty of Medicine of University of Indonesial \\ Cipto Mangunkusumo Hospital, Jakarta \\ ${ }^{4}$ Departement of Ophthalmology, Faculty of Medicine of University of Indonesial \\ Cipto Mangunkusumo Hospital, Jakarta \\ *Correspondence: melliaambarningrum@yahoo.com
}

\begin{abstract}
Background: Hypertension is a chronic disease which is characterised by increased systolic blood pressure $\geq 130 \mathrm{mmHg}$ and diastolic blood pressure $\geq 90 \mathrm{mmHg}$. Uncontrolled blood pressure could later result to the narrowing of the arteriole wall, which can interfere any organ vascularization. One of the complications of hypertension is retinopathy, which could affect cognitive function. The only blood vessel that we can observe directly from direct ophthalmoscope examination is the branches of artery or vein centralis retina. Objectives: This study assesses the correlation between retinopathy and cognitive impairment in hypertensive patients. Method: This was an assosiative study with a cross sectional design which involved subjects who had minimum experience of 5 years chronic hypertension. They were between $\geq 18$ years old and $\leq 65$ years old, who came to the renal hypertension or neurology clinic at Cipto Mangunkusumo hospital in the period of September - November 2016. The subjects must not have had any history of diabetes melitus, stroke, intracranial infection or tumor, head injury, parkinson, epilepsy and depresion. We used the MoCA-INA, $T M T A \& B$ and the Grooved pegboard for cognitive function testing. Retinopathy was assessed by using Heine mini 3000 ophtalmoscope. Result: A total of 47 subjects met the inclusion study consist of 27 (57.4\%) woman and 20 (42.6\%) man, and the median age was 57 years. The proportion of cognitive impairment were 45 (95.7\%) subjects, predominantly woman 26 (55\%). Memory was the most affected domain of cognitive impairment, with 44 (93,6\%) subjects affected. Many subjects had mild retinopathy which were characterized by arteriole-venule narrowing and arteriole-venule nicking. Statistical analysis using the Fisher test did not show any significant correlation between retinopathy and cognitive impairment in hypertension patients $(p=1,000)$. Conclusion: There were no significant correlation between retinopathy with cognitive impairment in hypertensive patients.
\end{abstract}

Keywords: Hypertension, retinopathy, cognitive impairment

\section{INTRODUCTION}

Hypertension is a chronic disease which is characterised by increased systolic blood pressure $\geq 130 \mathrm{mmHg}$ and diastolic blood pressure $\geq 90 \mathrm{mmHg}$ (Madhur, 2014; Kaplan, 2006). Based on the result of health research data base of health ministry of Republic of Indonesia year 2013 that prevalence of hypertension in adult which have been diagnosed by health worker equal to $9.4 \%$. As much $63.2 \%$ of cases of hypertension in the community are undiagnosed (Departemen Kesehatan Republik Indonesia, 2013). In 30\% of patients will be at risk of atherosclerosis and $50 \%$ of patients will experience organ damage within 8-10 years 
after the onset (Madhur, 2014). Uncontrolled blood pressure could later result to the narrowing of the arteriole wall, which can interfere any organ vascularization, such as eyes, kidneys and brain (Østergaard, Engedal, Moreton, Hansen, Wardlaw, Dalkara, et al., 2015; Theng, 2014). Ocular disorders in hypertensive patients is due to changes in the structure of blood vessels. Retinal arteries and its capillaries have an anatomical resemblance to blood vessels in the brain that exhibit autoregulation and tight junctions to maintain blood ocular barrier. So that the retinal blood vessels can be considered as a reflection of the brain's vasculature (Theng, 2014; Patton, Aslam, MacGillivray, Pattie, Deary, \& Dhillon, 2005). One of the complications of hypertension is retinopathy, which could affect cognitive function (Wolf, 2007; Galetta, Balcer, \& Liu, 2008; Waldstein, 2003) The only blood vessel that we can observe directly from direct ophthalmoscope examination is the branches of artery or vein centralis retina (Liew, Wang, Mitchell, \& Wong, 2008; Patton, Aslam, MacGillivray, Pattie, Deary, \& Dhillon, 2005). Cognitive function is a complex function involving various circuits in the brain that include orientation, attention, memory, language, visuospatial and executive functions. The presence of a disturbance in the function illustrates the presence of brain dysfunction.This study assesses the correlation between retinopathy and cognitive impairment in hypertensive patients.

\section{METHOD}

This was an assosiative study with a cross sectional design which involved subjects with chronic hypertension, who had minimum experience of 5 years. The age of the subjects were between $\geq 18$ years old and $\leq 65$ years old, who came to the renal hypertension or neurology clinic at Cipto Mangunkusumo Hospital in the period of September - November 2016. The inclusion criteria for this study were that the subjects must not have had any history of the following illnesses: diabetes melitus, stroke, intracranial infection or tumor, head injury, parkinson, epilepsy and depresion. The subjects were examined by anamnesis, general and neurological physical examination, cognitive function test and funduscopy. We used the Montreal Cognitive Assesment Indonesia (MoCA-INA), Trail Making Test A and B (TMT A\&B) and the Grooved pegboard for cognitive function testing. Cognitive impairment is established if the score of MoCA-INA $<26$ or the score of TMT A or TMT B or Groovedpegboard were under the normal score by age group from the preliminary study. Whereas retinopathy was assessed by using HEINE mini 3000 ophtalmoscope. Retinopathy was established when any of these criterias were observed: arteriol-venule narrowing, arteriolevenul nicking, crossing sign, retinal hemorrhage, microaneurysm, exudate or optic disc edema. The correlation between retinopathy and cognitive impairment was analyzed with Fisher test because the Chi-Square test requirement was not fulfilled.

\section{RESULT AND DISCUSSION}

A total of 47 subjects met the study criteria (Table 1) consist of $27(57.4 \%)$ woman and $20(42.6 \%)$ man, and the median age was 57 years. The proportion of cognitive impairment by MoCA-INA or TMT A or TMT B or Grooved pegboard were 45 (95.7\%) subjects, predominantly woman $26(55 \%)$. Memory was the most affected domain of cognitive impairment, with $44(93,6 \%)$ subjects affected, followed by language with $27(57,4 \%)$ subjects affected and psychomotor functions with $26(55,3 \%)$ subjects affected. Many subjects had mild retinopathy which were characterized by arteriole-venule narrowing and arteriole-venule nicking. Statistical analysis using the Fisher test did not show any significant correlation between retinopathy and cognitive impairment in hypertensive patients $(\mathrm{p}=$ $1,000)$. 
Among the 47 subjects which were involved in the study, 45 of them had retinopthy $(95,7 \%) . \quad 43(91.4 \%)$ subjects with retinopathy produced a low score in cognitive examinations. The result of this study is similar with the Atherosclerosis Risk in Communities Study by Wong et al, 1987, which concluded that retinopathy is correlated to low cognitive scores. Subjects with retinopathy showed lower Delayed Word Recall score, OR 2.6 and 95\% confidence interval: 1.3 - 2.91, microaneurisma had OR 3.00 (95\% confidence interval: 1.81 - 4.98), retinal bleeding had OR 3.39 (95\% confidence interval: 1.99-5.78) and soft exudat had OR 3.07 (95\% confidence confidence interval: 1.53-6.17).

A total of 47 subjects met the study criteria (Table 1). The median age was 57 (39-65) years, predominantly female was $27(57,4 \%)$. Most of the subjects in our study were educated for $\geq 12$ years and had systolic blood pressure between 120-159 $\mathrm{mmHg}$ (respectively $76,6 \%$ ), had diastolic blood pressure between 80-99 $\mathrm{mmHg}(51,1 \%)$, prolonged hypertension 5-10 years and regular medication (respectively $78,7 \%$ ) and no history of smoking $(57,4 \%$ ).

Table 1: Subject Characteristics

\begin{tabular}{lcc}
\hline Category & Quantity (n) & \% \\
\hline Age (year) & 1 & 2,1 \\
$23-44$ & 46 & 97,9 \\
$45-65$ & & \\
Sex & 20 & 42,6 \\
Male & 27 & 57,4 \\
Female & & \\
Education & 11 & 23,4 \\
$<12$ years & 36 & 76,6 \\
$\geq 12$ years & 7 & 14,9 \\
Sistolic blood pressure & 76 & 76,6 \\
$<120$ mmHg & 4 & 8,5 \\
$120-159$ mmHg & & \\
$\geq 160$ mmHg & 15 & 31,9 \\
Diastolic blood pressure & 24 & 51,1 \\
$<80$ mmHg & 8 & 17 \\
$80-99$ mmHg & & \\
$\geq 100$ mmHg & 37 & 78,7 \\
Duration suffering from hypertension & 10 & 21,3 \\
$5-10$ years & & \\
$>10$ years & 37 & 78,7 \\
Regularity of taking medicine & 10 & 21,3 \\
Yes & & \\
No & & 12,8 \\
Smoking & 6 & 57,4 \\
Yes & 27 & 29,8 \\
No & 14 & \\
History & & \\
\hline
\end{tabular}

The proportion of retinopathy was $45(95,7 \%)$ subjects, with arteriole-venule narrowing was 41 subjects, arteriole-venule nicking was 22 subjects and exudate was 3 subjects. The characteristics of retinopathy are shown in table 2. 
Table 2: Retinopathy Characteristics

\begin{tabular}{lcc}
\hline & Category & Quantity (n) \\
\hline Arteriole-venule narrowing & 41 \\
Arteriole-venule nicking & 22 \\
Exudat & & 3 \\
\hline
\end{tabular}

The proportion of cognitive impairment was $45(95,7 \%)$ subjects, predominantly female was $26(57,8 \%)$. Cognitive impairment based on MoCA-INA examination was found in $24(51 \%)$ subjects, TMT A examination was $40(85,1 \%)$, TMT B examination was 42 $(89,4 \%)$ and Grooved pegboard was $26(55,3 \%)$. There were many cognitive impairment domain based on MoCA-INA examination, the most was memory domain 44, language was 27, executive was 23, visuospatial was 21 and attention deficits was 12 subjects. Distribution of cognitive impairment are shown in table 3.

Table 3: Distribution of Cognitive Impairment Domain Based on MoCA-INA

\begin{tabular}{|c|c|}
\hline Cognitive domain & Quantity (n) \\
\hline Memory & 44 \\
\hline Language & 27 \\
\hline Executive & 23 \\
\hline Visuospatial & 21 \\
\hline Atention & 12 \\
\hline
\end{tabular}

A total of 43 subjects $(91.4 \%)$ with retinopathy are suffered cognitive impairment. Whereas 2 subjects (4.3\%) without retinopathy have cognitive impairment. Through fisher test obtained $\mathrm{p}$ value $=1,000$. In statistical analysis there were no significant correlation between retinopathy with cognitive impairment. The relationship between retinopathy with cognitive impairment is shown in table 4.

Table 4: Relationship Between Retinopathy with Cognitive Impairment

\begin{tabular}{|c|c|c|c|c|c|}
\hline & & \multicolumn{2}{|c|}{ Cognitive examination } & \multirow[b]{2}{*}{ Total } & \multirow[b]{2}{*}{$\mathrm{p}$} \\
\hline & & $\begin{array}{l}\text { Cognitive } \\
\text { impairment }\end{array}$ & Normal & & \\
\hline Retinopathy & $\begin{array}{l}\text { Yes } \\
\text { No } \\
\text { Total }\end{array}$ & $\begin{array}{c}43(91,4) \\
2(4,3) \\
45(95,7)\end{array}$ & $\begin{array}{c}2(4,2) \\
0(0) \\
2(4,3)\end{array}$ & $\begin{array}{c}45(95,7) \\
2(4,3) \\
47(100)\end{array}$ & 1,000 \\
\hline
\end{tabular}

*Fisher Test

\section{CONCLUSION}

There were no significant correlation between retinopathy and cognitive impairment in hypertensive patients. 


\section{REFERENCES}

Departemen Kesehatan Republik Indonesia. (2013). Laporan hasil riset kesehatan dasar Indonesia (Riskesdas). Badan Penelitian dan Pengembangan Kesehatan Kementerian Kesehatan Republik Indonesia.

Galetta, S.L., Balcer, L.J., \& Liu, G.T. (2008). Neuro-ophthalmologic anatomy and examination techniques. In : Kidd DP, Newman NJ, Blousse V, editor. Neuro-

Kaplan, N.M. (2006). Primary hypertension : Pathogenesis. In: Caplan's clinical hypertension. 9th edition. Philadelphia: Lippincott Williams \& Wilkins.

Liew ,G, Wang, J.J., Mitchell, P, \& Wong, T.Y. (2008). Retinal vascular imaging a new tool in microvascular disease research. ahajournals. 1:156-61.

Madhur, M.S. (2014). Hypertension: practice essentials, background, pathophysiology. Sept 30 [accessed on March15, 2016].

Available in: http://emedicine.medscape.com/article/241381-overview\#a1

Østergaard L, Engedal TS, Moreton F, Hansen MB, Wardlaw JM, Dalkara T, et all. (2015). Cerebral small vessel disease : Capillary pathways to stroke and cognitive decline. JCBFM. July 30.

Patton, N., Aslam, T., MacGillivray, T., Pattie, A., Deary, I.J., \& Dhillon, B. (2005). Retinal vascular image analysis as a potential screening tool for cerebrovascular disease: a rationale based on homology between cerebral and retinal microvasculatures. $J$ Anat.;206:319-48.

Theng K. (2014) Ophtalmologic manifestations of hypertension: acute and chronic changes to the eyes. Mar 21 [accessed on March 15, 2016. Available in: http://emedicine.medscape.com/article/1201779-overview//showall

Waldstein, SR. (2003). The relation of hypertension to cognitive function. Available in: www psychologicalscience.orgophthalmology. Philadelphia: Butterworth Heinemann Elsevier. h. 12-15.

Wolf S. (2007). Hyprtensive retinopathies. In : Joussen AM, Gardner TW, Kirchhof B, Ryan SJ. editor. Retinal vascular disease. Germany: Springer; h. 717-19.

Wong, T.Y., Klein, R., Sharrett, A.R., Couper, D.J., Klein, B.E., Liao, D.P., et al. (2002). Cerebral white matter lesions, retinopathy, and incident clinical stroke. JAMA.;288:1. 